\title{
Transport through track etched polymeric blend membrane
}

\author{
KAMLENDRA AWASTHI, VAIBHAV KULSHRESHTHA, B TRIPATHI, N K ACHARYA, \\ $M$ SINGH and Y K VIJAY* \\ Department of Physics, University of Rajasthan, Jaipur 302 004, India
}

MS received 10 June 2005

\begin{abstract}
Polymer blends of polycarbonate (PC) and polysulphone (PSF) having thickness, $27 \mu \mathrm{m}$, are prepared by solution cast method. The transport properties of pores in a blend membrane are examined. The pores were produced in this membrane by a track etching technique. For this purpose, a thin polymer membrane was penetrated by a single heavy ion of $\mathrm{Ni}^{7+}$ of $100 \mathrm{MeV}$, followed by preferential chemical etching of the ion track. Ion permeation measurements show that pores in polymeric membrane are charged or neutralized, which depends upon the variation in concentration of the solvent. The $V-I$ curve at concentration, N/10, shows that the pores are negatively charged, whereas at concentration, $N / 20$, the linear nature of $V-I$ curve indicates that the pores approach towards neutralized state and on further concentration, N/40, the pores become fully neutralized, consequently the rectifier behaviour of pores has been omitted.

The gas permeability of hydrogen and carbon dioxide of this membrane was measured with increasing etching time. The permeability was measured from both the sides. Permeability at the front was larger than the permeability at the back which shows asymmetric behaviour of membranes.
\end{abstract}

Keywords. Polymer blend; ion irradiation; track etched membrane; ion current; gas separation.

\section{Introduction}

Polymer materials are technologically important for research because of their diverse applications i.e. filtration, protective coating, nanoscale designing etc. The transport of penetrant through a membrane depends upon the nature of penetrant as well as structural features of the membrane material (Barbari et al 1988), moreover, these can be modified using different techniques for special applications. Attempts have been made by irradiation of swift heavy ions in polymers. The irradiation of swift heavy ions in polymers changes the physical and chemical properties (Avasthi et al 1998). Swift heavy ions transfer energy to the polymer essentially by inelastic (electronic) process while elastic (nuclear) energy transfer is, in general, negligible for pristine polymers. But nuclear energy loss gains importance with subsequent polymer destruction, when tracks start overlapping. The energy transfer leads to excitation and ionization of molecular chains leading to radical formation to side or main chain bond scissioning and also to cross linking of polymer chains. Thus the bombardment of energetic ions results in the change in the free volume properties having a strong correlation with the macroscopic properties of material. The damaged zones created along the path of high energy ions are called latent tracks and contain material with highest degree of disorder (Ferry 1990). The tracks are enabling to pass the gas molecules

*Author for correspondence (yk_vijay@ sancharnet.in) or liquids so it is required to preferentially etch to enlarge the size. Both the track and bulk etching takes place in the irradiated membrane.

The production of porous membranes stands out among other applications of track etch technique as nano filter (Fleischer et al 1975). Asymmetric membrane of poly (ethylene terephthalate) has been studied using $I-V$ characteristics (Apel et al 2001). The asymmetric membrane was produced by etching of irradiated membrane with two different etchants placed on either side of the membrane (Shtanko et al 1999; Apel et al 2001). Track etched membrane can be applicable in the versatile area of scientific and industrial research. Irradiation of a polymer membrane by heavy ions and subsequent chemical etching creates a membrane having an array of nano channels (Fleischer et al 1975; Trautmann et al 1996).

In the present work, we aimed to prepare track etched membrane of blend type. This blend polymer membrane was made of polycarbonate $(25 \%)$ and polysulphone $(75 \%)$ of thickness, $27 \mu \mathrm{m}$. The membrane was characterized by ion and gas permeability.

\section{Experimental}

\subsection{Membrane preparation}

The polycarbonate and polysulphone materials were obtained in granular form from M/s Gadra Chemicals, Bharuch. 
For preparing blends, the desired quantity ( $1: 3)$ of material was dissolved in dichloromethane. The membranes of thickness, $30( \pm 2) \mu \mathrm{m}$, were prepared by solution cast method with different concentrations. The details of solution cast method has been given elsewhere (Vijay et al 2002). The membrane was pealed off and dried in low vacuum at $50^{\circ} \mathrm{C}$ for $10 \mathrm{~h}$ to completely remove the solvent.

\subsection{Irradiation}

The membranes cut in desired size to fit the permeability cell were irradiated by $\mathrm{Ni}^{7+}$ ion of $100 \mathrm{MeV}$. The irradiation was performed in general purpose scattering chamber (GPSC) at the Nuclear Science Centre, New Delhi. The fluence of ion beam was $10^{7}$ ions $/ \mathrm{cm}^{2}$. The uniformity was achieved using rotating flywheel attachment, the details having been given elsewhere (Vijay et al 2000-01).

\subsection{Chemical etching}

The irradiated membranes were etched chemically in $6 \mathrm{~N}$ $\mathrm{NaOH}$ at $60^{\circ} \mathrm{C}$. The etching time was increased with the step of $1 \mathrm{~min}$ and after every etching the membrane was washed thoroughly. The etchant changed periodically so that concentration of etchant remained the same during the experiment and the temperature of etchant was also constant throughout etching (Spohr).

\subsection{Permeability measurements}

The ion permeation through membrane can be characterized by permeability cell, as shown in figure 1 , which measures the ion current across the membrane. The polymeric membrane separated the electrolyte and de-ionized water and $\mathrm{Pt}-\mathrm{Cu}$ electrode was dipped in the cell. By applying the voltage, the permeation of particular ion depends upon the characterization of membrane i.e. the available free space in the form of tracks. Double distilled and carrier

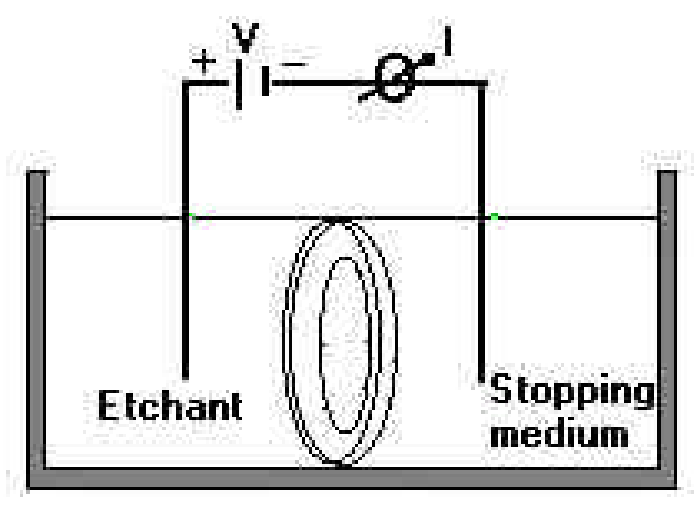

Figure 1. Ion permeability cell. free de-ionized water was used as a standard solvent, which was obtained from Millipore ultra pure water system. The ion current was recorded corresponding to the voltages with the help of Keithley 238 high current source measure unit (Apel et al 2001).

The permeability of hydrogen and carbon dioxide was measured from both the sides of the membrane i.e. ion incidence side and ion emergence side. The flow rate was measured using permeability cell and the permeability was calculated using Fick's formula (Vijay et al 2003). The penetration of gas took place across the membrane due to the pressure gradient (Yadav et al 2003). We applied $30 \mathrm{psi}$ pressure from one side of the membrane.

\section{Results and discussion}

Polycarbonate and polysulphone are both the glassy polymers having a common ring structure (bisphenol-A) in their repeating unit. Polysulphone has an additional ring structure and $-\mathrm{SO}_{2}$ group in its repeating unit. The blend of these polymeric materials may form some new bonds. The permeability of polymers depends on the operating conditions such as temperature, pressure and composition as well as on structural features of the materials. The permeability increased with etching time and at a particular etching time a large enhancement in permeability was observed. The time at which the permeability rapidly increased is known as critical etching time. It depends on irradiant parameters like mass, energy and dose of irradiant. Permeability also depends on thickness of the membrane and molecular size of the gas that we use. Swift heavy ion (SHI) produces tracks along its path when passing through the polymer. The modified polymer chain structure in blends creates an additional space to pass the permeant and the etching of these blends depends on the characteristics of polymers.

The voltage current characteristics are shown in figure 2. Ion permeation measurements show that the pores created in polymeric membrane are charged or neutral, which depends upon the variation in concentration of the solvent. The $V-I$ curve shows that at concentration $0 \cdot 1 \mathrm{~N}$, the pore wall is negatively charged and the pore rectify the ion current in contrast to $0.025 \mathrm{~N}$, when the polymer surface seems neutral and $V-I$ characteristics becomes practically linear. At zero voltage, the negative current is obtained which indicates the ion transfer through membrane due to concentration difference. The technique offers to create device based on nanostructure. The ion channels that function as a diode for ionic current, they have preferential direction of ion flow and block almost completely ions moving in the other direction.

The permeability of membrane increases rapidly at the critical etching time as shown in figure 3. The critical etching time is $35 \mathrm{~min}$ for $10^{7}$ ions $/ \mathrm{cm}^{2}$. Here the permeability at the front and back sides is different for both gases, 


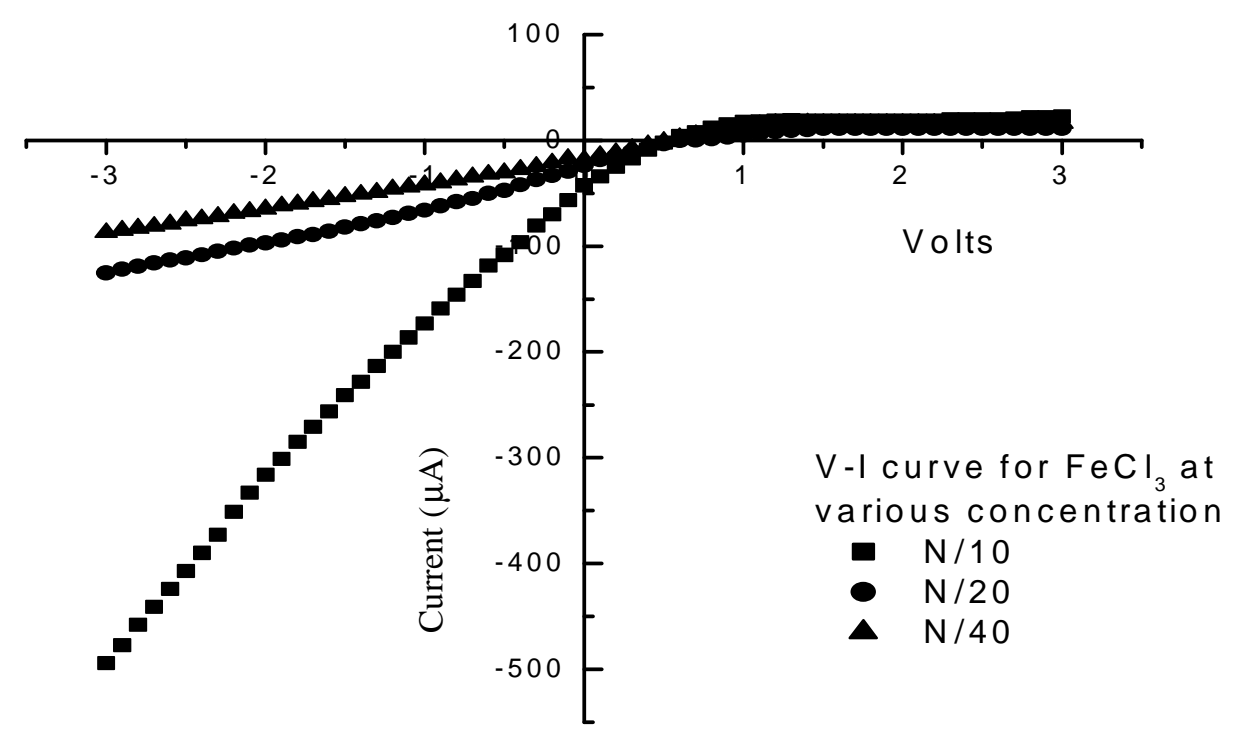

Figure 2. $\quad V-I$ characteristics of membrane at different concentrations of electrolyte.

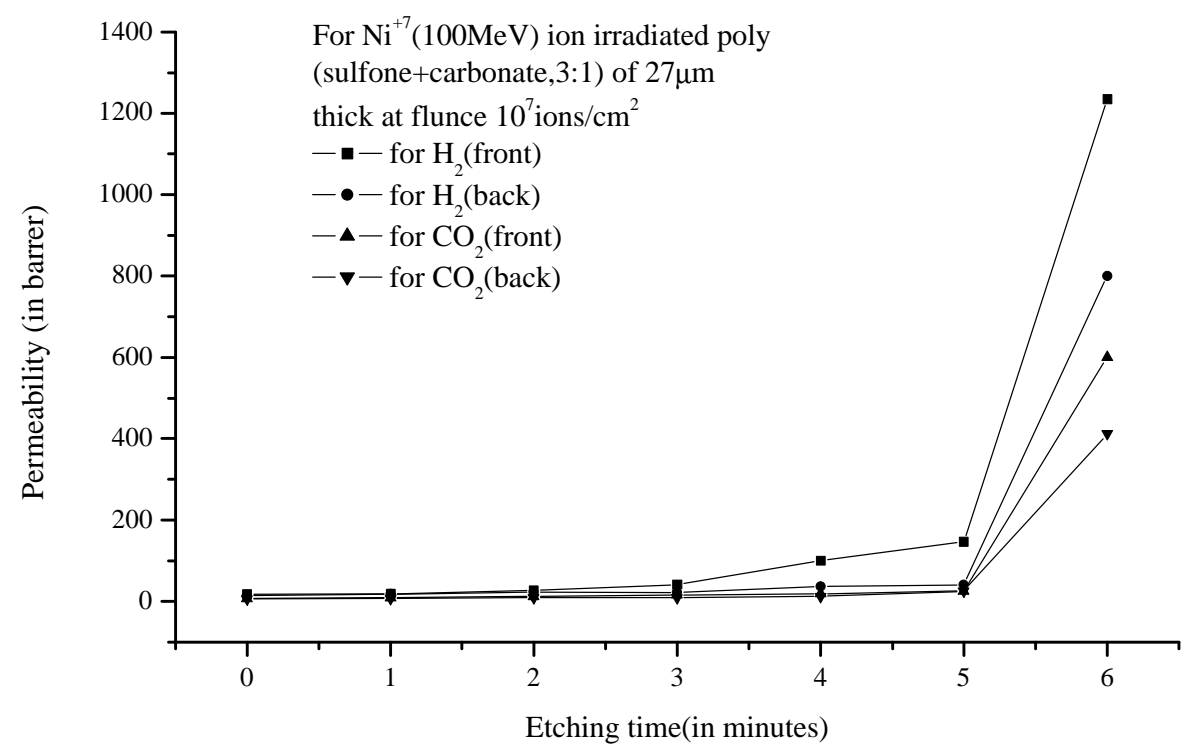

Figure 3. Gas permeability of hydrogen and carbon dioxide gases at different etching times.

which shows the asymmetrical behaviour of the membranes. In order to study the effect of molecular size dependence of permeability, measurements for $\mathrm{H}_{2}$ and $\mathrm{CO}_{2}$ gases have been performed at the same conditions of temperature and pressure. The $\mathrm{CO}_{2}$ molecules are larger than $\mathrm{H}_{2}$ molecules, so less flow rate and correspondingly lower permeability was observed. By increasing the etching time, the permeability of both gases increased.

\section{Conclusions}

We have characterized the ion flow through pores prepared by track etching. Depending on the concentration of the electrolyte, asymmetric pores in a blend membrane, made of polycarbonate and polysulphone, rectify the ion current. We have shown that the effect of ion current rectification depends on the surface charge of pore, which has been modified by the concentration of feed solution. The permeability of the gases from the front and back sides are different; permeability at the front is higher than at the back side which shows the asymmetrical behaviour of the membrane. Ion irradiation, etching conditions and chemical structure of material play an important role. Possible applications may include the separation of charged particles and drug release as well as examination of translocation of biomolecules. 


\section{Acknowledgements}

The authors are indebted to the Nuclear Science Centre, New Delhi, for ion irradiation and the Ministry of NonConventional Energy Sources, New Delhi, for providing financial assistance for the work. One of the authors (KA) is thankful to Dr U N Kharul, NCL, Pune and Dr Zuzanna Siwy, University of Florida, Florida, for fruitful discussion.

\section{References}

Apel P U, Korchev Y E, Siwy Z, Spohr R and Yoshida M 2001 Nucl. Instrum. \& Meth. Phys. Res. B184 337

Avasthi D K, Singh J P, Biswas A and Bose S K 1998 Nucl. Instrum. \& Meth. Phys. Res. B146 504

Barbari T, Kores W and Paul D 1988 J. Polym. Phys. 26709

Ferry J D 1990 Viscoelastic properties of polymers (New York: John Wiley \& Sons Inc) 3rd ed.
Fleischer R L, Price P B and Walker R M 1975 Nuclear tracks in solids: Principles \& applications (Berkeley: Univ. of California Press)

Shtanko N I, Kabanov V Y, Apel P U and Yoshida M 1999 Nucl. Instrum. \& Meth. Phys. Res. B151 416

Spohr R (GSI Darmstadt, Planckstr, 1, D-64291 Darmstadt), European Research Training Network EuNITT Report 2.11

Trautmann C, Bouffard S and Spohr R 1996 Nucl. Instrum. \& Meth. Phys. Res. B116 429

Vijay Y K, Wate S, Acharya N K and Garg J C 2002 Int. J. Hydrogen Energy 27905

Vijay Y K, Wate S, Acharya N K, Bhahada K, Kothari A, Barua P and Awasthi D K 2000-2001 Annual Report, Nuclear Science Centre, New Delhi

Vijay Y K, Acharya N K, Wate S and Avasthi D K 2003 Int. J. Hydrogen Energy 281015

Yadav P K, Kulshrestha V, Mangal R K, Acharya N K and Vijay Y K 2003 Solid State Phys. (India) 46709 